longed operation, and, if so, free drainage will probably do all that is necessary. If the patient be in sufficiently good condition to permit a search for the rupture, and it can be found, it may be closed by fine silk or catgut sutures ; but, as a rule, it will be wise to open and drain the gall bladder at the same time. Should marked cholecystitis be found the question of cholecystectomy may be worth considering, but when the patient is in a critical condition it is a mistake to attempt too much, and, as a rule, cleansing and free drainage will be all that are necessary or advisable at the time, the removal of the cause being left until the patient is better able to bear a prolonged operation.

1BRITISH MEdical Jou REFERENCES.

JOURNAL, 1895, i., p. 977. 2 Ref. Gumprecht, Deut. Bed. Woch. 1895, No. 15. 3 Progres Medical, 1886. 4 Comptes Rendus Soc. Path., 1876, p. 453. 7 Lancet, March 2nd, 189 g $^{2}$ Rev. de Chir., 1895, p. 665 9 Soc. Biol. de Paris, December 2nd. 1893. 10 Ibid., December 23rd, 1893. 11 Zeit. f. Heilk., Band xv, p. 199. 12 Netter and Martha, Arch. de Physiol., vol. ix, 1886 .

\section{THE MILROY LECTURES}

\section{ON Q UAR A N'T I N E. \\ Delivered before the Royal College of Physicians of London, March, 1897.}

By W. COLLINGRIDGE, M.A., LL.M., M.D., Medical Officer of Health for the Port of London.

[Amstract.]

Dr. Milroy's Study of Quarantine.

I was led to choose the subject of quarantine for these lectures not only because I deem it to be of the utmost practical importance to a commercial country, but also because of the close relation of the subject with the name of Dr. Gavin Milroy, the founder of these lectures. To his labours to overthrow an obsolete and oppressive system, and to further the interests of commerce without jeopardising the public health, is due to a large extent the present free and unrestricted intercourse enjoyed with all parts of the world by our merchant navy. Though it was not his lot to see the full fruition of his work, his name will always be honourably associated with the public health defence.

\section{Definition}

In considering the question of quarantine it is important to define the term, inasmuch as the word has been applied indiscriminately to many different systems. Limiting the word to preventive measures designed to prevent the importation of disease into a country by means of maritime commerce, it may be defined as "the enforced detention and segregation of vessels arriving in a port, together with all persons and things on board, believed to be infected with the poison of certain epidemic diseases for specified periods." At tirst such periods were purely arbitrary, and bore no reference to the possible incubation period of the diseases against which they were directed. Later, with the advancement of medical science, there was some attempt in a crude way to make the detention correspond with the supposed duration of incubation or latency of the poison. The essential point of quarantine at its earliest inception up to its fully developed existence at the present day is that it estimates the danger, and thereupon the precautions to be taken, according to the state of health of the port from whence the vessel has arrived, and has no reference to the condition as regards health or sickness of the vessel and its inhabitants. Though quarantine has been employed as a protection against many diseases, originally it was against the danger of plague only that it was directed.

Early Quarantine Regulations.

The first known law for the seclusion of persons from in. fected districts for a probationary period was enacted under the Emperor Justinian in 542. The earliest definite regulations against the spread of disease are those contained in letters sent by Duke Bernados to the prefects in 1374, when plague was devastating Lombardy, in which it was ordered that any person wio should be attacked with any disease should forthwith leave the city or camp in which he was at the time, and should go into the fields or the woods until he either died or was set free; and further following exactly the idea of the Jewish Levites the priests of the parish churches were ordered under severe penalties to examine the sick, and report the nature of their sickness to certain officers appointed for the purpose. Those who attended on the sick were ordered to remain isolated for at least ten days after the death of a patient before they held any communication with other persons. None but those appointed for the duty were to be allowed to attend upon the sick under penalty of confiscation of goods and life. In 1383 , when the plague again invaded Lombardy, Bernados ordered that no persons should be allowed to enter his kingdom from any infected place under penalty of the yoke (sub poena furcarum); while in I 399 John Galeaz, Duke of Milan, for the same reason had guards placed at the gates of the city with instructions to prevent anyone entering who had come from a plague-stricken district. It was at the same time enacted that no house in which a case of plague had occurred should be again inhabited until it had been purified by fire, and freely opened up for eight or ten days. These, however, were but solitary instances of precautionary measures. While trade was small and confined within narrow limits the danger from infection, scarcely yet believed in, called for no extraordinary measures of defence. Soon commenced the great movement of the Crusades. Whatever the motives of those who took part in them, one great result was the opening up of trade with the East.

The laws of quarantine, at first very imperfect and very varied in their form and restriction in various States, all alike had their origin and bases in the one fundamental idea -namely, the doctrine of communication of disease by means of contagion.

According to Boccaccio, Florence had adopted measures for its preservation from imported disease in 1348; but to the Venetians must be given credit for the first complete code of quarantine regulations. Venice was at that time the great centre of trade with the East, and its inhabitants were therefore more exposed to the importation of disease than those of any other State. According to Baker, ${ }^{1}$ it is probable that their first regulations were issued as early as 1127, but in 1448 a complete code was issued which served as a model for all others up to a very recent period. It laid down as a principle that plague-against the introduction of which quarantine was established-was a contagious disease capable of being conveyed by contact, and by contact alone as regards persons, and capable of engendering a contagious matter-a fomes-capable of adhering to certain inanimate substances, of being retained by them for an almost indefinite time without losing its activity, and, on the other hand, incapable of attracting itself to other inanimate substances, and which might consequently be handled with absolute impunity and security. All merchants and persons coming from the Levant were compelled to remain in the house of St. Lazarus ${ }^{2}$ for a period of forty days before admission into the city.

\section{Origin of British Quarantine Regulations.}

The merchants settled in Turkey appear to have established certain aefinite precautions against the plague, and British merchants, who were not established there until close on the sixteenth century, doubtless influenced by their predecessors, at once began to adopt similar protective measures. These however, were optional on their part, and were not required by the law of the land.

In 1603 an Act for the "relief and ordering of persons affected with plague" was passed, but this provided only for the isolation of persons in the country, and contained no provisions as to maritime quarantine. In the year 1636 the question was referred to the College of Physicians, and certain Directions were issued by them. The second article states :

It is likewise necessary that there be care taken that neither man nor goods may come from any suspected places beyond the seas, or in places within the land, without certificate of health, or else either to be sen suddenly away, or to be put to the pest house (or such like place) for orty days, according to the custom of Italy

When these articles were republished in 1665 , the changes made justify the inference that quarantine had been at that time definitely established, and it was no longer necessary to recommend its imposition 
British Quarantine Legislation.

The first quarantine Act in England was passed in the ninth year of the reign of Queen Anne. Up to this period all quarantine regulations were issued by the King in Council without the intervention of Parliament. This is clearly shown in the preamble of the Act. This Act, like nearly all the subsequent ones, was passed under the influence of panic, the plague then raging in the Baltic.

Upon another alarm of plague at Marseilles in 1720 a second Quarantine Act was passed to continue in force for three years only, and the outbreak of plague at Marseilles was the occasion for the passing of two Acts in the following session. All these three Acts, being temporary, expired, whereupon the Act of Queen Anne again came into force. In the first year of the reign of George II another Act, nearly word for word with that of George I, was passed. The power of prohibiting intercourse with any country for twelve months was conferred, and also power to prevent any person coming from an infected place under a penalty of $£ 500$. The exporter of goods was to forfeit double their value in addition to loss of ships and goods.

This Act again was only temporary, and expired in $173 \mathrm{t}$ In consequence, however, of the appearance of plague abroad, it was revived in 1733 for a further period of two years. On it expiry in 1735, and until 1753, the Act of Queen Anne was once more the quarantine law of the land. In 1752 Parliament once more dealt seriously with the question, and two Quarantine Acts were passed in the following year, and came into force twelve months later. This was the first time that the Legislature had approached the subject deliberately, and without the fear of an epidemic hanging over them, and as a consequence the Acts passed were far more thorough and complete.

In the 26 chap., George II, the 12th clause enacted "That no goods nor merchandise liable to retain the infection of the plague, and coming from the Levant without a clean bill of health, shall be landed in Great Britain until it shall appear to the satisfaction of His Majesty that the same goods or merchandise have been sufficiently opened and aired at the lazarettos of Malta, Ancona, Venice, Messina, Leghorn Genoa, Marseilles, or one of them." The powers as to dealing with individuals were very vaguely expressed: "They shall be subject to such orders as they receive from proper officers."

In spite, however, of the care bestowed upon the Quarantine Act, it was still from an administrative point of view very unsatisfactory. In all cases the details were left to the Privy Council-a body which had neither the time nor the means to attend to them properly.

In 1805 another Act was passed which, while in no way interfering with the existing system of quarantine, materially modified the charges which had been so serious a burden to the commerce of the country. A report of the Select Committee on the foreign trade of the country in 1824 states that the quarantine charges in many cases amounted to 35 per cent. of the value of the cargo, and one instance is given in which they exceeded 90 per cent., although there had been no sickness on board the vessel.

The last Act in this country was the sixth George IV cap. 78 , which repealed all former regulations and enacted that all vessels arriving from any places from whence $\mathrm{His}$ Majesty, by the advice of his Privy Council, shall have declared it probable that the plague or other infectious disease or distemper highly dangerous to the health of $\mathrm{His}$ Majesty's subjects may be brought, and all persons and goods shall be liable to quarantine.

By the 39 and 40 Vict., Cap. 36, the powers of the Privy Council were ordered to be carried out by Her Majesty's Commissioners of Customs; and this continued until the repeal of the Quarantine Act in 1896. Long before this, however, the enormously-increased importance of our foreign trade and the obvious futility of the strict enforcement of quarantine had excited the attention of thinking men.

Dr. McLean was one of the principal movers in this direction, and his able statement of opinion led the House of Commons in 1817 to refer the matter to a Select Committee, which arrived at the opinion that the plague is "communicable by contact only, and differs in this respect from epidemic fever," and added that "they saw no reason to question the validity of the principles upon which such (quarantine) regulations appear to have been adopted." But Sir William Pym, the Superintendent of Quarantine, recommended considerable relaxation of quarantine, giving as his reason that he had never known a single instance of a case of plague occurring in a vessel from the Levant, and his belief that, with due regard to ventilation, infection would not spread. Twenty years later Sir William Pym could say: "That there was no evidence to show that a single case of plague had ever been known to occur in any country from the manipulation of suspected or infected merchandise landed in a lazaret." The records of lazarets also proved that the disease seldom or never spread, even from the sick, to any other of the inmates or to the officials of the establishment.

Up to the beginning of the present century quarantine had been directed against plague only. Yellow fever was at that time scarcely thought of, and cholera was not recognised as a danger to Europe. The experience of quarantine (183I-1832) as a protection against cholera was most unfavourable, and so clearly was this recognised that on the second visitation in 1847 it was not relied upon.

\section{INTERNATIONAL RegUlations.}

A proposal for a general Congress of delegates from States having ports on the Mediterranean had been made by the French Government in 1838 , but fell through owing to various difficulties which arose. A further attempt by the British Government to bring about a general conference in 1843 failed, owing to the view of Austria that such conference would be premature until exact information had been obtained from a Committee of Medical Authorities appointed to report as to :

. The maximum and minimum terms of quarantine for persons.

2. The terms of quarantine necessary for goods and merchandise ; and 3. The best measures for disinfection of objects susceptible of contagion.

Towards the close of 1844 a Commission was appointed by the Royal Academy of Medicine in France to report upon the whole subject. After a deliberation of more than twelve months they presented a most exhaustive report. Among its conclusions were :

That plague had arisen spontaneously in Egypt, Syria, Turkey, and n other countries but could always be reasonably attributed to certain determinate soil in low crowded, badly ventilated dwellings, especially in a warm moist climate and atmosphere, exposed to the actions of putrescen mimal and vegetable matter, unwholesome and insufficient food, and great physical and moral wretchedness.

That pical and not to any great extent transmissible beyond or away from epidemic foci for the following reasons:

That it was doubtful whether goods or clothing can convey plague durinat was certain that they cannot after.

That the period of incubation was as a general rule three to five days.

The Commission advises :

$x$. That for vessels having a medical officer on board from Egypt, Syria, or Turkey with a clean bill of health, the period of quarantine should be a full ten days, calculating from the date of departure, provided that no case had occurred on board. That with a foul bill this period should be fifteen days for a healthy vessel.

2. For merchant vessels without a medical man the same periods should be imposed, but that they should in all cases date from the time of arrival. The report itself is exceedingly valuable and instructive, but its conclusions do not in any way justify the severity of the practica recommendations.

In 1865 was published the eighth report of the Medical Officer of Health of the Privy Council, and the remarks therein made by Sir (then Mr.) John Simon, ${ }^{3}$ marking by their clearness, power, and scientific accuracy a distinct epoch in the position of this country, remain and will remain as a record of his acumen and far-sightedness in this as in many other directions. But quarantine was not yet got rid of. Originally established to prevent the importation of disease, when this object was shown to be futile the system was still retained in order to prevent interruption to trade. It was clear that while other countries kept up the practice any official abandonment would only lead to an indiscriminate quarantining of British vessels. That this was no imaginary danger has been shown on many occasions.

In 1853 the countries where quarantine was most rigorously carried out were Spain, Portugal, Greece, and Sweden. As soon as cholera appeared in this country Spain called upon Gibraltar to impose quarantine upon all arrivals from our ports, and on account of some delay all communication with the mainland was at once cut off except such as was carried on by smugglers, and in self-defence the authorities were 
compelled to yield. This same pressure during the present year has caused Gibraltar to impose quarantine upon vessels from Indian ports. Any hesitation to comply would have involved a complete cessation of the important defence works in course of construction there.

Again, in 1825, when some vessels with foul bills of health were admitted to pratique by order of the Government the whole United Kingdom was put in quarantine by the Mediterranean Powers, and every arrival from Great Britain subjected to a lengthy detention. And to quote one more recent in stance, the Helene, a small German vessel which arrived in London in August, 1893, with two cases of cholera on board was refused pratique at a South American port nine months later, the reason assigned being that she had not yet undergone quarantine, having been only subjected to disinfection in this country.

At the close of the cholera epidemic in 1851 on the invitation of the French Government, delegates attended at Paris from France, Great Britain, Austria, Russia, Turkey, Greece, Spain, Portugal, and some other Powers to consider the question. They decided :

That henceforth only two degrees of quarantine should be recognised, namely, quarantine of observation and quarantine of rigour, the quaranine of suspicion being abolished.

T.1at only two forms of bill of health should be allowed, namely, clean and foul and that these should be granted after the health of the port of and foul, and the port of departure has becn properly ascertained, and not on conjecture as hereand and passengers in consequence or the healt of the port of departure, during the regard should be paid to the condition of health or sickness was to be directed against the infected country generally.

The diseases against which quarantine was to be employed were reduced to three, namely, cholera, yellow fever, and plague.

It is worthy of note that Austria opposed the inclusion of cholera, on the ground that she had tested quarantine against it in 1831 , and found it not only useless but dangerous. England, France, and Sardinia alone opposed quarantine entirely, and stated that they had retained it only in consequence of the position of other European Powers. Spain and Portugal, while admitting that the utmost protection could be afforded by measures of general sanitation, held that till these have been universally carried out reliance must be placed on compulsory segregation.

Although the deliberations of the Conference lasted for more than three months, the total result was unsatisfactory in the extreme.

It had begun to be understood in this country that whatever advantages were supposed to be gained by quarantine could be more effectually yained by other and more reasonable methods. In 1848 , when the old system was discontinued upon the recommendation of Dr. Southwood Smith it was explained that, in place of the rigorous detention of vessels from infected ports with their crews and passengers for a lengthened period, a system of strict sanitary supervision of the vessels themselves and of all persons on board by a medical officer should be substituted,

The Social Science Quarantine Committee in 186r, after having submitted a long list of questions to Her Majesty's Customs and others, from the information thus obtained formulated a most valuable report, which was published by the Board of Trade. It recommended :

r. That under ordinary circumstances vessels which have had no sickness during the voyage, and are in good sanitary condition on arrival, should be admitted to free pratique without regard to the health of the port of departure.

2. When any detention of a vessel is necessary, either from the fact of sickness existing or on account of the foul or unwholesome condition of the vessel, a careful examination should be made of her and of all the persons on board by the quarantine medical officer, who should have power and should be charged with the responsibility of adopting suc measures as eacli case demands The healthy should not be detained, and the sick should be removed to hospital as speedily as possible. Where small-pox exists on board ship all unprotected persons should be vaccinated.

3. Vessels from abroad should be required to pump out their bilge water and clean their bilges before entering harbour, and the hold should be aired so far as possible before arrival.

4. Before a bill of health is given an examination should be made as to the sanitary condition of the vessel and the health of the crew, and the results of such examination noted on the bill of health.

5. Medical quarantine officers should be required to keep accurat records of all matters relating to quarantine, and to prepare an annual report thereon.

In I868 a strong deputation, representing the medical profession, presented a memorial to the Privy Council, in which they urged that the subject of quarantine had for the last twenty years been under the notice of the public, and that the present system had utterly failed during its trial in $1831-$ 32 , and had moreover been productive of great inconvenience. In 1873, so far as cholera was concerned, quarantine was officially abandoned, and medical inspection substituted by an order of the Local Government Board.

The International Sanitary Conference of Vienna.

In 1874 another International Conference was held at Vienna, the object being "to arrange among the Powers interested compulsory regulations having as their object to bring about a perfect uniformity in the measures to be adopted against this common danger," and also to consider as to the advisability of establishing a permanent or temporary International Sanitary Commission. Twenty European States were represented, also Persia and Egypt.

This Conference reaffirmed ihe decisions arrived at at the Conference in Constantinople in 1866 that cholera originated in India, that it was transmissible by human agency, and that it might be conveyed from an infected place by means of clothing which had been worn, and especially by such as had belonged to persons suffering from cholera. They unanimously decided that the disease could be conveyed by fluids, especially by water. There was a want of unanimity on the question of danger of infection from merchandise. The incubation period of cholera was fixed at a few days, a week at the outside.

As to quarantine, a resolution of a Committee (appointed to consider the question) to the effect that when cholera had broken through the chief points of irruption, quarantines in the ports of Continental Europe were useless, inasmuch as land communications deprived them of all their value, was carried by a majority of 12 to 8 only. In the majority were Great Britain, Germany, Russia, Austria-Hungary, and Italy, France being the only Power of the first rank among the minority. The next resolution of the Committee, "Under these circumstances it is necessary to establioh in the ports of Europe, instead of quarantine, a rigorous sanitary inspection of every vessel coming from an infected port, in accordance with the following regulation," was also adopted. Thus for the first time was medical inspection formally adopted in the place of quarantine by a majority of the European Powers, and in the case of those who still clung to the old system some important modifications were adopted. While, however, so large a minority refused to accept the decisiun of the majority, it was obvious that but little could be accomplished.

The British Cholera Regulations.

In 1883 regulations were again issued by the Local Government Board for dealing with cholera, and these contained several important moditications from the order of 1873 . The duty, in the first place, of deciding as to the state of health of the vessel on arrival devolved, as heretofore, upon the cfficers of HIer Majesty's Customs, and the subsequent treatment of any vessel found to be infected upon the port sanitary authority. Independent authority was, however, given to the medical officer of health to visit and examine any vessel from an infected port, whether she had previously been visited by the Customs or not, and a form of certificate was givan for the medical officer to use in any case in which he had reason to believe a vessel was "infected" within the meaning of the order. Upon the delivery of this certificate the vessel was entirely under the control of the medical officer of health.

In 1890 regulations were ggain issued, and power given to the medical officer of health to require in the case of an infected vessel (defined in the order as a vessel in which there is, or has been during the voyage or during the stay of such ship in a port in the course of such voyage, any case of cholera) the name and address of all passengers on board who were found on medical inspection to be healthy before they were ailowed to leave. By forwarding such names and addresses to the sanitary authority of the district to which they were about to proceed, it was placed in the power of each district by tirnely notice of such arrival to protect itself by keeping such persons under observation so long as deemed advisable. 
The Draspen Conference.

In 1893 was held at Dresden the last International Sanitary Congress, at which were represented Germany, AustriaHungary, Belgium, Denmark, Spain, France, Great Britain, Greece, Italy, Luxemburg, Montenegro, the Netherlands, Portugal, Roumania, Russia, Servia, Sweden and Norway, Switzerland, and Turkey. England was professionally represented by Dr. Thorne Thorne, the Medical Officer of the Local Government Board, to whose able advocacy of medical inspection the Conference in a great measure owes its successful results.

Three committees were appointed-the first to deal with the duties of a Government when cholera appeared in a country, the second to deal with the measures necessary to prevent cholera entering a country or spreading from one part of a country to another, while the third devoted itself to the Danube traffic. The convention was finally signed by the delegates of Germany, Austria-Hungary, Belgium, France, Great Britain, Italy, Russia, Switzerland, Luxemburg, Montenegro, and the Netherlands. This Convention, which will of necessity exercise a powerful influence upon all sanitary regulations of this country, will last for five years from the date of ratification. It will be renewed every five years by tacit consent, unless renounced by one of the high contracting parties six months before the expiration of this term. Such renunciation will affect only those countries which shall have notified. The Convention will remain in force for the other States.

Although the agreement arrived at does not establish a perfect system it marked a prodigious advance, and it must not be forgotten that there were great difficulties to be overcome and many prejudices to combat which could only be met by concession whenever possible without sacrificing the broad general principles involved.

The keeping under observation of healthy persons arriving in infected ships was thus agreed to by England, on the distinct understanding that this in her case would not involve any actual detention, but would be covered by the forwarding of the name and address to the sanitary authorities of the district to which they were about to proceed.

Shortly after this protocol had been signed a Bill was prepared to abolish quarantine in this country, but, owing to the change of Government and various other difficulties, it was not until September, 1896, that the Public Health Act became law. By this act the powers of the Privy Council to deal with cholera, yellow fever, and plague were transferred to the Local Government Board, who were thereby empowered to make regulations for the various sanitary authorities concerned.

These regulations now in force practically extend the cholera regulations with certain modifications to these three diseases. If a vessel is found to be infected by the officer of Customs, she is reported to the medical officer of health, who detains her and deals with her at his discretion. He has, moreover, the power of boarding any vessel for the purpose of ascertaining whether she is so infected without the previous intervention of the Custom authorities.

Thus for England quarantine has been formally abolished, and our protection henceforth against the importation of infectious disease will be medical inspection, without any vexatious detention of a healthy vessel merely because she has arrived from an infected port.

This shortly has been the history of quarantine in this country, and it now remains for time and experience to demonstrate to other countries the value of our system in order to induoe them to accept the same conclusions. With many this will be readily brought about, while others will have more difficulty in arriving at the same opinions.

I Nautical Magazine, r896, REFERENCES.

the preal Magazine, 1896, p. 092. 2 Hence the term "lazarette" in use athe present day. There has always been considerable doubt as to the origin of the period of forty days which gave rise to the name of the system. It seems probable that it was derived from the Jewish ceremonial, and was continued under various systems and laws until it became a settled period, the origin of which was lost, and the only justiication for which was its antiquity. 3 Report of the Medical Officer to the Privy Council, page 40.

$$
\text { (To be continued.) }
$$

NOTE ON INTESTINAL GASES, PHXSIOLOGICAL AND PATHOLOGICAL.

By H. MUIR EVANS, M.D.LQND., Lowestoft

IT is hardly necessary to reassert that there are only three possible sources of gas in the gastro-intestinal tract, namely, (I) air swallowed, (2) gases transfused from or secreted by the blood, (3) gases arising frnm the fermentation of food stuffs. Apart from gases the result of fermentation, it is usually held that the most frequent cause of gastric flatulence is air swallowed with the food or saliva; in support of this statement we are told that the nitrogen in the gases of such cases occurs in about the same proportion as it exists in atmospheric air, and that carbonic acid gas is present in the same proportion as the oxygen in the air. The oxygen is presumed to be absorbed, and the carbonic acid gas transfused from the blood. This one can readily understand if one remembers that roo volumes of arterial blood contain 20 volumes of oxygen and 40 volumes of carbon-dioxide, while in 100 volumes of venous blood there are 8 to 12 volumes of oxygen and 46 of carbon-dioxide, the nitrogen in both arterial and venous blood being merely I to 2 volumes to the 100 .

In intestinal gases we find again that nitrogen is in a greater proportion than all the other gases. In meteorism resulting from a case of typhoid, according to C. A. Ewald, an analysis by puncture gave 8.3 per cent. carbonic acid gas and the remainder nitrogen. In a woman with a tight stricture of the rectum the gases obtained by means of a stomach tube consisted of 6.9 per cent. carbonic acid gas, II.6 per cent. hydrogen, and 81.03 per cent. nitrogen. I do not intend to deal with the more simple problem of the presence of marsh gas after eating leguminous vegetables, or with the formation of sulphuretted hydrogen. The rapid production of intestinal gases after abdominal operations, in peritonitis and gastritis, in hysteria, in certain affections of the lungs and heart, renders the theory of an excretion of gases from mucous membranes of the intestines exceedingly probable.

I could enumerate from my notebooks numbers of cases in which such an explanation seems the only possible solution of the problem. As a step in the investigation of this subject, it occurred to me that in fishes we had an example of a physiological secretion of gases. The sound or air bladder in the fish is in some cases not connected in any way with the intestinal tract, although in many it is connected with the csophagus, and in others, as the herring, with the caudal extremity of the stomach. The fact that in many species this connection is entirely absent, and in all cases is but a mere pore, renders it certain that the gases in the so-called air bladder must be obtained from the blood.

Since the cod is supplied with a particularly large sound, which has absolutely no communication with the intestinal tract or gills, I chose it for investigation. The wall for the most part consists of a dense, white, non-vascular, homogeneous membrane, but within the sound at one spot is a lobed, cauliflower-like, vascular organ, which lies free in the cavity of the sound. The function of this organ is apparently that of the secretion or absorption of gases. The next step in the investigation was carefully to collect and analyse the gases obtained from a fresh cod. This was done by means of an aspirating needle attached to an india-rubber bag, similar to those used in the making of air balls for children. I entrusted two specimens to Mr. Lincolne Sutton, public analyst of the city of Norwich, and the result of his analysis was: Bag 1 : oxygen, 12.18 per cent.; nitrogen, 87.82 per cent. In Bag 2: oxygen, 17.95 per cent.; nitrogen, 82.05 per cent. If these gases contained carbonic acid gas, it was a mere trace, too small to measure. In his report Mr. Sutton remarked that the atmospheric gases in solution in natural waters contained about 34 per cent. of oxygen, and, on the contrary, in these specimens the proportion of nitrogen to oxygen was greater than in atmospheric air. This most interesting fact concerning gases, the origin of which is without doubt the result of a secretive process from the vessels of the vascular organ within the sound, suggests a series of problems upon which further investigation may throw valuable light.

In the first place, one can at present only speculate on 